\title{
INTERVENCIONES
}

\section{Sobre las ideas socialistas en el Río de la Plata en el siglo XIX}

\author{
Hernán M. Díaz \\ Universidad de Buenos Aires, Argentina - Centro de Estudios Históricos de los Trabajadores y las Izquierdas \\ hernandiaz59@gmail.com \\ ORCID: 0000-0003-4351-1647
}

Titulo: On socialist ideas on the Río de la Plata in the 19th century

Resumen: En el presente artículo se discute la denominación "socialismo romántico", utilizada por Horacio Tarcus en una trilogía, publicada entre 2016 y 2020, que trata sobre la recepción de las ideas socialistas en la Argentina en el siglo XIX. Se realiza también una discusión acerca del socialismo anterior a Marx y su vínculo complejo con el romanticismo como movimiento literario o como filosofía de la historia.

Palabras clave: Tarcus - socialismo - siglo XIX

Abstract: This article discusses the name "romantic socialism", used by Horacio Tarcus in a trilogy, published between 2016 and 2020, which deals with the reception of socialist ideas in Argentina in the 19th century. There is also a discussion about pre-Marx socialism and its complex link with romanticism as a literary movement or as a philosophy of history.

Keywords: Tarcus - socialism - 19th century

Recepción: 6 de abril de 2021. Aceptación: 12 de agosto de 2021

DOI: https://doi.org/10.46688/ahmoi.n19.326

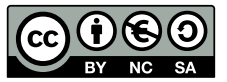

Obra bajo licencia Creative Commons 4.0 International (Atribución - NoComercial - Compartirlgual) 


\section{$* * *$}

Horacio Tarcus ha terminado de publicar un tercer volumen sobre la recepción de las ideas del socialismo francés en el Río de la Plata, abarcando desde la generación de 1837 hasta el fin del siglo XIX. Estos tres volúmenes (Tarcus, 2016 y 2020) son un producto, ampliado y reelaborado, de la tesis doctoral del autor, cuya primera aparición editorial fue el libro Marx en la Argentina, publicado en 2007 y que, en rigor, remitía al último tramo cronológico del estudio de la recepción del socialismo en la Argentina decimonónica. Así, estos cuatro volúmenes forman un cuadro amplio de los primeros pasos de las ideas de reforma social en nuestro país, desde la simple repetición o reconocimiento de las nuevas doctrinas hasta la conformación, a fin de siglo, de corrientes orgánicas que buscaban reconstruir en nuestro suelo las organizaciones proletarias ya desarrolladas en Europa.

Los tres volúmenes que analizamos hoy, El socialismo romántico en el Río de la Plata (1837-1852) y los dos volúmenes de Los exiliados románticos. Socialistas y masones en la formación de la Argentina moderna (1853-1880), forman un conjunto homogéneo, relativamente distante de Marx en la Argentina, ya que estos tres nuevos libros indagan alrededor de unos grupos y personajes poco o nada transitados en la historiografia, al menos desde el punto de vista de su recepción del socialismo. La obra de Tarcus se instala, de esa manera, como un punto clave en la comprensión de la prehistoria del socialismo y el anarquismo argentinos $\mathrm{y}$, en muchos aspectos, será también una obra de referencia, dada la escasez y la parquedad de las fuentes consultables. Las observaciones, las sugerencias e incluso las críticas que desarrollaremos no obstan para reconocer que la historia de los orígenes del socialismo en la Argentina encontrará en estos textos su comienzo insoslayable.

En el primer libro, el autor busca analizar la recepción del socialismo en el Río de la Plata en la época de Rosas, rastreable en la obra de Echeverría, Alberdi, Sarmiento, Miguel Cané (padre) y Andrés Lamas. En el ámbito montevideano (por eso la apelación en el título al Río de la Plata), se releva un curso de economía politica brindado por Marcelino Pareja, quien reproducía conceptos de Sismondi, y la obra de Eugène Tandonnet, partidario de las teorias de Charles Fourier. La recepción de las obras de los primeros socialistas (en particular, franceses) registra, en todos los casos, una variedad de actitudes: desde la cerrada crítica de Sarmiento (a quien, sin embargo, Tarcus también adjudica "fascinación" por ese cuerpo de ideas) hasta la aceptación variable de algunos postulados, pasando por el simple registro o la lectura atenta. Esa variedad es observable también en las fuentes leídas por los diferentes politicos y periodistas rioplatenses, ya que se pueden encontrar desde 
los grandes sistemas socialistas, como Saint-Simon o Fourier, hasta sus continuadores y vulgarizadores como Pierre Leroux o Victor Considerant, o incluso pensadores que no eran en absoluto socialistas (como Jouffroy, Cousin, Lerminier, Michelet, Quinet, Lamennais), pero que el autor considera que forman parte del "pensamiento social" de la época.

Las lecturas de Pierre Leroux, y en mucha menor medida de Saint-Simon, permitieron a Echeverría y a Alberdi dejar de lado el enfoque meramente institucional y político de los primeros liberales argentinos, para tratar de forjarse una idea global de las fuerzas sociales y económicas que operaban en nuestro país. Acusaron a los unitarios de querer trasplantar los esquemas republicanos franceses sin conocer las particularidades del país en que actuaban y sin preocuparse de que maduren las condiciones que hicieron posible el liberalismo en una Europa desarrollada. Echeverría, en particular, utilizó por momentos la palabra "socialismo" (Dogma socialista) para referirse a una concepción política que atendiera a las necesidades de todos los sectores de la sociedad y no solamente a los de la clase culta de Buenos Aires.

El segundo y el tercer libro tienen un enfoque acotado a cuatro biografias de personajes poco conocidos, aunque a lo largo de su historia aparecen también otros personajes menores que también reciben la influencia del socialismo o de alguna teoría reformista afin. El primer volumen de Los exiliados románticos está dedicado al chileno Francisco Bilbao y al español Bartolomé Victory y Suárez. Bilbao actuó desde muy joven en las luchas políticas de su país, se exilió en Francia donde fue testigo de la revolución de 1848, regresó a Chile donde participó de la Sociedad de la Igualdad, con la que encabezó una revolución en 1851 contra Manuel Montt y se instaló finalmente en Buenos Aires, ejerciendo un periodismo de combate. Influido por las ideas de Lamennais, Michelet y Quinet, tuvo especial preocupación por conectarse con los sectores de artesanos y trabajadores. En sus textos utilizó un lenguaje ambivalente, cargado de metáforas y lleno de idealismo, acorde con el romanticismo de la época (Tarcus, 2016, p. 120). Pregonó la soberanía de la razón, lo cual lo acercaba más a Guizot que al socialismo (ídem, p. 134). Fue quizás el primero en hablar de "América Latina", se opuso a la invasión francesa a México y en lo doméstico fue un enemigo de las políticas elitistas y oligárquicas.

Victory y Suárez, luego de mezclarse en las luchas republicanas de España, llegó a la Argentina en 1857. Dirigió en 1863 el periódico El Artesano, que promovía el desarrollo profesional y la asociación entre los obreros, y publicó una breve colección de libros, entre los que incluyó una traducción de un texto de Étienne Cabet, El comunismo, con un prólogo del mismo Victory donde planteaba su discrepancia con las ideas del francés, aun cuando le pareciera importante conocerlas. También 
se vinculó a los primeros intentos de asociación obrera con carácter mutual y sindical, participando en la Sociedad Tipográfica Bonaerense y redactando alguno de sus manifiestos.

El tercero y último libro contiene las biografias del francés Alejo Peyret y del español Serafin Álvarez. Peyret participó de la revolución de 1848 y con el golpe de Luis Bonaparte debió exiliarse en nuestro país, donde residió hasta su muerte. Ejerció un periodismo de crítica democrática y fue administrador de la colonia San José, en Entre Ríos. Leyó y adhirió a las ideas de Proudhon, particularmente a su idea del federalismo, a la que asoció con la política de las provincias del interior argentino. Se inscribió en la política de fomento de las colonias migratorias de Urquiza, con quien mantuvo una relación política y económica. Vinculado de manera general al socialismo de su época, participó en el congreso fundacional de la II Internacional, en París en 1889, en representación de la militancia de Argentina, pero Tarcus se encarga de subrayar que Peyret estaba en Francia con un encargo oficial del gobierno, llegó por casualidad al congreso y no estaba munido de ninguna credencial que lo acreditara como representante.

El español Serafin Álvarez, nacido en Granada, estudió abogacía en Madrid y estuvo vinculado con los sectores democráticos y, tangencialmente, con el primer anarquismo de la Asociación Internacional de Trabajadores. Se tuvo que exiliar después de la experiencia republicana, en 1874, pero ya había escrito en su país El credo de una religión nueva, donde exponía su propia visión de un socialismo elemental, basado en la solidaridad y en la asociación, con fuertes tintes cristianos. Más que ofrecer una visión original del socialismo, Álvarez realizaba alli un sincretismo donde convivian diferentes fuentes del socialismo premarxista, y lo que predominaba era el componente moral más que el económico o el político. Ya en Argentina, se desempeñó en el periodismo, donde escribió páginas muy críticas contra el dominio de la oligarquía vacuna y la falta de democracia real para las grandes mayorías. A fin del siglo no adhirió al naciente Partido Socialista e incluso polemizó con esta nueva organización, pues concebía ya el socialismo como la marcha general de la ciencia y del estudio de la humanidad en su conjunto. Su vínculo y su influencia sobre el movimiento obrero fue así poco significativa.

El "Epílogo" del tercer libro sirve como marco teórico general para los tres volúmenes. Alli el autor concluye que ha apelado al método de la biografia intelectual para iniciar el camino de una historia conceptual del socialismo en el siglo XIX. En este sentido, no entiende el "socialismo" como una idea, sino que éste se corporiza en una serie de personas y corrientes que sostienen, argumentan y combaten alrededor de un concepto que se despliega en la historia. Lo que importa son los usos que los agentes concretos han realizado con esas ideas. De todas formas, 
si la historia conceptual es el marco teórico explícito que sostiene la investigación, en el análisis puntual de cada uno de los actores de esta historia parece prevalecer más el recurso a la teoría de la recepción, que a la manera de Hans R. Jauss indaga en las formas de apropiación de las ideas y su traducción en tierras americanas.

Para agregar una dimensión crítica, que no quita mérito a la investigación realizada, creemos que no se debe confundir el concepto con la palabra. El concepto de "socialismo" existe más allá y más acá de la utilización de la palabra que lo designa. Más allá, porque la idea de socialismo se forjó desde mucho tiempo antes de que Pierre Leroux inaugurara el término (en un sentido negativo) en 1833, y era llamado, por ejemplo, "nuevo mundo" por los sansimonianos o "armonía" por Fourier. De la misma manera que la palabra "comunismo" nace o, mejor, se consagra en 1840, con el famoso brindis de los comunistas en Belleville, pero ya Babeuf hablaba de los almacenes y tierras comunes, o bien la noción era conocida como "comunidad de bienes" por los reformadores sociales aun cuando no adherian a ella. Y más acá, porque la utilización de ese concepto (y Tarcus insiste en que busca analizar los usos a que dio lugar) es inescindible de un conjunto de consideraciones ideológicas que lo acompañan, del marco metodológico en el que se inscribe, de las prácticas políticas a que da lugar, del proyecto social específico que quienes lo utilizan aspiran a realizar. Y aunque se insista en que se analiza el concepto de socialismo a través de sus usos, creemos que por momentos se desatienden una serie de aspectos que hacen que se debilite la historia del socialismo y de las reformas sociales en la Argentina, incluyendo en un mismo agrupamiento expresiones completamente disimiles.

El conjunto de corrientes de reformadores sociales que desarrollaron sus teorías antes de la revolución de 1848 (y que extendieron su influencia directa por varias décadas) fueron denominados por Engels "socialistas utópicos". El pequeño libro donde los describió en escasas páginas tuvo un enorme éxito en Europa y el mundo entero, grabando a fuego una denominación que no hacía justicia a las enormes diferencias que se podian observar entre las distintas corrientes, que incluian tanto a reformistas como a revolucionarios, tanto a construcciones utópicas como a análisis profundos y visionarios. La propia denominación "socialismo utópico" postulaba que detrás de ese nombre existía una unidad, aunque sea en un nivel conceptual profundo, que lo diferenciaba y contraponía con todo el socialismo posterior. Hemos creído demostrar en un libro reciente (Díaz, 2020) que, por un lado, en el interior de esos movimientos las contradicciones politicas eran insolubles en una categorización general y, por el otro, que muchas o todas las corrientes socialistas previas a Marx y Engels reaparecieron de manera constante 
en la historia de las luchas sociales y que no habia ninguna diferencia epistémica o filosófica que justificara el confinamiento de una serie de pensadores a la infancia del movimiento socialista.

Tarcus acepta la idea de la unidad del socialismo premarxista e intenta renombrarlo como "socialismo romántico". Ya hemos desarrollado, en el libro citado (ídem, pp. 134-139) la crítica a la utilización indiscriminada de ese término. Agregaremos algunos elementos más. El romanticismo fue un movimiento artístico y cultural esencialmente individualista, quizás la expresión más alta, en la historia de la humanidad, de exaltación del individuo, en consonancia con una sociedad (el régimen burgués) que nacía estructurada sustancialmente en el atomismo del egoísmo general y autorregulado. El socialismo, en cambio, en todas sus variantes, nace como una contraposición al individualismo como base de la organización social, y parte justamente de la búsqueda de condiciones para hacer coincidir el interés general con el interés particular. Para ello busca un basamento científico que, como toda ciencia, elimine el factor subjetivo en la resolución de los problemas sociales. Incluso la misma palabra que denomina al movimiento, "socialismo", es un derivado de la palabra "asociación" con la que el nuevo movimiento se opone a la guerra de todos contra todos, característica de la sociedad capitalista. Es cierto que el romanticismo se opuso eventualmente al "burgués", pero de la misma forma como se opone el orfebre y el artesano al trabajo industrial, automatizado e impersonal. Es antiburgués cuando quiere protestar por el empobrecimiento que la gran industria produce en el artesano. El romanticismo lucha por la libertad del individuo culto, y la masa le parece un conjunto de ignorantes perfectamente compatibles con la alienación del trabajo fabril.

Como acertadamente dijo Victor Hugo, "el romanticismo es el liberalismo en literatura". Es decir que hay que considerar la clara continuidad entre el pensamiento liberal y la tendencia romántica en el arte. El socialismo, en cambio, en todas sus formas, nació como una crítica y una contraposición al liberalismo individualista. Pero para Tarcus, "el socialismo nació romántico" (2016, p. 24), o sea que el romanticismo incluye, comprende, subsume y determina al socialismo. Identifica al romanticismo con "la época", incluso con la moda, todo queda subsumido en esa corriente intelectual, con lo cual le quita al socialismo de los origenes toda posibilidad de autonomía con respecto a la "ideología dominante".

Es cierto que hubo algunas pocas expresiones en el interior del socialismo que abrevaron en el individualismo y en el humanismo iluminista, pero fueron marginales frente al conjunto del movimiento obrero y de izquierda y, por cierto, enemigas del "socialismo". Pierre Leroux, particularmente, cuando "inventó" la palabra socialismo lo hizo de ma- 
nera crítica, para censurar el "exceso de igualitarismo" que implicaba el movimiento que nacía frente a sus ojos, y lo opuso al individualismo (propio de los liberales) como el error contrario y simétrico. Leroux, inventor del término, renegó así del socialismo, hasta que años después lo convencieron de que la palabra ya englobaba tantas corrientes diferentes que era más conveniente influir desde adentro del movimiento que desde afuera. ${ }^{1}$

Se cae así en la mitología que considera que la infancia del socialismo, antes de Marx, era el delirio de un grupo de críticos soñadores, que maldecían por impotencia y se dejaban arrullar por las ilusiones de un futuro perfecto (véase el famoso texto de Lenin, 1946, pp. 5-12), y no se estudia el cúmulo de esfuerzos teóricos y prácticos que permitieron que más tarde surgiera un movimiento obrero fortalecido con una teoría específica de transformación social. Hablar de "socialismo romántico" es toda una elección ideológica: significa, en vez de entender el socialismo como elaboración colectiva, subsumir ese movimiento en la "filosofia del siglo" encarnada en el individualismo. Se insiste con la "filosofia de la época" como un determinante forzoso que impregnaría toda producción teórica y todo intento práctico de reforma, pero para demostrarlo se hace tabla rasa con las características concretas y reales que el movimiento socialista tuvo en su momento. Es verdad, como dice Marx, que la ideología dominante es la ideología de la clase dominante, pero si todas las expresiones ideológicas las sometemos a ese paraguas general, entonces no existen manifestaciones revolucionarias y el mismo marxismo sería parte de la ideología dominante. Que exista una ideología dominante (¿y el romanticismo lo seria?) no significa que determine toda producción teórica. Las ideologías se contraponen unas a otras de la misma manera que las clases sociales: el socialismo no es una mera variante del liberalismo, y menos aún del romanticismo.

Se destaca en Tarcus la intención de incluir cualquier influencia o recepción del socialismo anterior a Marx dentro de una denominación que sirva como reemplazo al calificativo canonizado por Engels. Esa sería la intención original para proponer la denominación de "socialismo romántico". Pero si el romanticismo determinó cultural e ideológicamente las formas que debía adoptar el primer socialismo, entonces también el socialismo de Marx debería ser denominado romántico. Si no se incluye el socialismo "científico" en esa categorización, entonces lo que se está queriendo plantear es que el socialismo previo a 1848 fue casi una obra de literatos, de poetas, y en todo caso de liberales. Esto, claramente,

1. Tampoco se puede afirmar que Leroux representaba un "socialismo desde abajo" (Tarcus, 2016, p. 128). Lo más que se puede decir es que era parte de la "izquierda" francesa de la época. 
no tiene nada que ver con las primeras generaciones de reformadores sociales que dieron origen al marxismo.

No queremos plantear que no exista, eventualmente, un romanticismo con aires socializantes o también socialistas que se inclinaron al romanticismo. Obviamente existieron muchos escritores románticos con sensibilidad por las clases pobres (pero ese simple sentimiento no es socialismo) y algunos socialistas que abandonaron las preocupaciones por el conjunto de la sociedad (como Pierre Leroux, pero no muchos más) y se refugiaron en las falsas consignas de los liberales: democracia, humanidad, libertad. Las gradaciones son atendibles, pero aquí no estamos hablando de una escala de grises sino de un intento por reducir el socialismo a una versión altruista del liberalismo, cuando en realidad el socialismo, como conjunto, nació y se desarrolló en una oposición tajante con el individualismo burgués.

Por otra parte, el conjunto de personajes que estudia Tarcus en su trilogía ni son todos socialistas, ni son todos románticos. ¿Hasta qué punto se puede insistir en el "sansimonismo" de Echeverria, más allá de que a su manifiesto lo llamó "Dogma socialista"?2 ¿Y qué tienen de románticos Bartolomé Victory y Suárez, Alejo Peyret o Serafin Álvarez?

Tarcus retoma la interpretación de José Ingenieros, quien consideraba que la generación de 1837 (sobre todo Echeverria y Alberdi) había sido formada en el sansimonismo. El único objetivo de esta clasificación consiste en acercar a Echeverría y Alberdi a una especie de "premarxismo", que nos permitiria entonces reverenciar a esos padres de la patria sin culpa. La misma operación pretendió hacer Milcíades Peña cuando denominaba a Alberdi un hegeliano sin Hegel. Pero por más planteos democráticos que hayan realizado los dos próceres, no se puede dejar de señalar su inclusión en el corazón del naciente liberalismo argentino.

Se insiste en que Echeverría, en su estadía parisina, conoció a los sansimonianos, y que, en ocasión de la redacción de su Dogma socialista, no podía desconocer el significado que el término "socialismo" había adquirido en Europa hacia 1846 (Tarcus, 2020, II, p. 275). En vez de "socialista", Echeverría podría haber utilizado el término "social", que no tenía las mismas implicancias, y eso demuestra, afirma Tarcus, que la inclusión del término "socialista" fue deliberada y programática. Pero aquí hay un doble error. Es verdad que el socialismo para 1846 incluía un sinfin de corrientes, la mayoría opuestas al liberalismo, pero todas esas corrientes pugnaban por una reforma social que mejore la

2. Efectivamente, no es sólo en el título que Echeverría utiliza ese término. En el "Prólogo" afirma: "andamos en busca de una luz de criterio socialista" (Echeverría, 1873: 110; subrayado en el original). Pero, como veremos, es muy poco frecuente y no es definido en ningún momento. 
situación de la enorme masa de proletarios que el liberalismo había abandonado a la suerte que le deparaba el "mercado". Por otra parte, el término "social" también era usado en los movimientos europeos de la época como sinónimo de "preocupado por la suerte de los pobres". Así, la propuesta de "una Europa social" o "un Estado social" era la consigna central para amplios sectores de las masas, que se habian apropiado de un término que parecía protegerlos.

¿Acaso Echeverría proponía algún tipo de reorganización de la sociedad argentina en beneficio de los gauchos? ¿Quizás tenía una propuesta de crear asociaciones cooperativas, o bien organizar el trabajo en beneficio de los más pobres? De ninguna manera. Lo que propone Echeverria, para superar la dicotomía entre los liberales bonaerenses que ignoraron la realidad del país y los federales bonaerenses que gobernaron de manera dictatorial, es recurrir a un símbolo: Mayo. La fecha de la revolución de 1810 debe ser un rasgo de unión que una a todos los argentinos. Echeverría inventa así la política "democrática" del siglo XX: unir al país detrás de un símbolo polifacético, que les permita seguir administrando el país en beneficio de la misma minoría que lo administraba antes. Su propuesta politica es encaminar a la sociedad tras un simbolo-fetiche, que asegure la fraternidad aparente y otorgue el poder a la oligarquía de manera consensual. El problema de Echeverría es cómo crear una clase dirigente aceptable y digerible, no de qué manera beneficiar a las masas. Sólo busca una ficción de democracia que evite la manifestación de las contradicciones de clase. En ningún sentido de la palabra "socialismo" podemos encontrar este significado.

¿Soluciones económicas o sociales que beneficien a las mayorías? Para Echeverría, la Argentina debe desarrollar en lo posible la elaboración de las materias primas que se exportan. No entregarlas en bruto sino dar las pieles curtidas, las lanas escardadas, etc. "No nos hallamos en estado de fabricar con nuestras lanas paños, ni con nuestras pieles y crines cosas útiles, porque nos faltan elementos" (Echeverria, 1981: 266). No debemos ser un país industrial, agrega, pero hay que lograr un mayor valor agregado y una tecnificación del campo. Como reformador, ni siquiera llega a la insistencia en la industria de Saint-Simon: como gran hacendado, hace la defensa típica en su época de la conservación de la situación pastoril de nuestra economía, agregándole alguna mínima elaboración para mejorar los términos de intercambio con las grandes potencias industriales.

La palabra "socialista" en su Dogma, su gran capacidad literaria y su exilio crearon una confusión retrospectiva sobre Echeverría, magnificaron su reformismo democrático y velaron las intenciones originales de la Asociación de Mayo, confesadas en sus mismos escritos: lograr que 
Rosas encabece el movimiento de reconciliación de la patria, aceptando una apertura paulatina del juego político.

La interpretación más coherente sobre el supuesto socialismo de Echeverria la cita el mismo Tarcus (aunque se opone a ella) y proviene de un filósofo liberal, Coriolano Alberini (1934). Echeverría no es en absoluto sansimoniano, afirma Alberini: no sigue a Saint-Simon y tampoco a sus discípulos. En todo caso sigue a Leroux, agrega el filósofo, pero no a la "sustancia" de su pensamiento sino a sus aspectos más superficiales. La palabra "socialista", usada por muchos escritores de distinto color político, es sinónimo de "social". En ese sentido, agregamos nosotros, es más una influencia vaga del socialismo que una demostración del sansimonismo de los primeros liberales argentinos.

Pero dejemos hablar a Echeverria (1981: 253), en una carta pública a Pedro De Ángelis, fechada un año después de la publicación del Dogma socialista:

¿Dónde, en qué página de mi libro ha podido hallar Ud. rastro de las doctrinas de Fourier, Saint-Simon, Considerant y Enfantin? ¿Por qué no me la cita?

¿Hay algo más en todo él que una fórmula económica de Saint-Simon adoptada generalmente en Europa, y aplicada por mí a toda la sociabilidad? ¿Y de aquí deduce Ud. que yo soy Falansteriano y Sansimoniano a un tiempo? ¿Qué puede haber más ridículo y extravagante que semejante deducción de su caletre?

Toda la generación del 37, incluidos Echeverría, Sarmiento y Alberdi, leyeron a los socialistas franceses, pero siguieron sobre todo a Pierre Leroux, que nació políticamente en el liberalismo doctrinario, fue después sansimoniano durante un año y medio y se convirtió rápidamente en un humanista democrático, defensor de la propiedad y enemigo del movimiento reformista que él ayudó a denominar como "socialista" (para él, en sentido crítico). Si en el Leroux humanista encontramos ecos de los socialismos previos, no van más allá de una consideración compasiva de los miserables, que abarcaban al 90\% de la sociedad de su tiempo.

Las ambigüedades que pueda suscitar en 1846 el término "socialismo" no pueden ocultar el hecho de que Echeverría, al igual que Alberdi y que Sarmiento, son los pilares de la construcción del Estado oligárquico de la Argentina. Lo que sí queda claramente documentado es que toda esa generación, incluidos Cané, Andrés Lamas o Marcelino Pareja, leyeron a autores socializantes franceses de la época, pero los leyeron junto a, y en concordancia con, los autores liberales que tenían una pose de reconocimiento de los problemas sociales, como Quinet, 
Lamennais o Michelet, ninguno de los cuales puede figurar en una historia del socialismo.

Se repite en los tres volúmenes un mecanismo de identificaciones que por momentos parecen exageradas. Marcelino Pareja es "un Sismondi rioplatense", Francisco Bilbao es "un Lamennais", Victory y Suárez "un cabetiano", Alejo Peyret "un Proudhon de la colonización". No señalamos una cuestión de estilo: se trata de identidades exageradas, presentes casi todas en los títulos de los capítulos, que no parecen marcar una verdadera congruencia entre el modelo y la copia. Francisco Bilbao fue verdaderamente un hombre de revolución, un político decidido y que se ubicó en la izquierda del arco ideológico de Chile y de la Argentina, incluso de Latinoamérica. Pero Lamennais fue el intento tardío de un ex ultramontano de arrebatarle al socialismo creciente las banderas de defensa de los proletarios, reencauzándolos por las sendas de la Iglesia, aun cuando esta institución lo expulsó de sus filas. Es un antecedente de la doctrina social de la iglesia, no del socialismo. Bilbao puede tener influencias de Lamennais, pero su actividad política lo lleva mucho más lejos que el predicador herético francés. No es un Lamennais, es mucho más.

Victory y Suárez no es cabetiano en ningún sentido, y de la misma biografia que traza Tarcus se desprende que no hay identidad entre uno y otro. Tradujo a Cabet (el folleto "Comment je suis communiste"), pero en el mismo prólogo aclaró que no coincidía con las ideas del francés. ¿Acaso Victory se reclamaba comunista? ¿Quizás propuso colonias perfectas en algún paraje rural de América o de Europa? En absoluto. Digamos al pasar que tampoco Cabet puede ser considerado "un demócrata" (Tarcus, 2020, II: 272). Su utopía comunista (basta con leer su Viaje a Icaria, pero también conocer su puesta en práctica en Texas) tiene poco que envidiarle a la pesadilla estalinista del siglo XX.

Finalmente, tampoco la lectura de Proudhon hace de Alejo Peyret un proudhoniano. Él sí era un demócrata, y se ubicó en el lugar políticamente más radical que le ofrecía la Argentina, pero la opción por el federalismo y su traslación a nuestras pampas no parece que permita realizar una operación de identificación tan estricta como aparece ya en el título del capítulo.

Un comentario al margen merece la mención de la masonería en los títulos (Tarcus, 2020) y en varias de las biografias. Aunque algunos personajes incursionan en la masonería (y también será el caso, más adelante, en el Partido Socialista), no queda claro qué rol tiene en la difusión del socialismo. En las conclusiones finales del libro no se ofrece una reflexión sobre el término. Entendemos que el secretismo de la masoneria impide muchas veces al historiador evaluar la dimensión del fenómeno, pero si sólo se trata de un ámbito de "sociabilidad" y no hay 
evidencias de un registro de obediencia o de jerarquías que ponga a esa enigmática sociedad en el primer plano, no se entiende que el tema esté presente en el título general de la obra. El registro de su importancia no se condice con la expectativa que se abre en el encabezamiento de los dos últimos volúmenes.

En definitiva, estamos frente a un esfuerzo de gran envergadura por rastrear desde las mínimas lecturas del socialismo francés hasta aquellos que siguieron algunos de sus postulados, antes de la aparición de los internacionalistas en la década de 1870 o de los socialistas y anarquistas en la última década del siglo. Algunas de las biografias, sobre todo las incluidas en los volúmenes dedicados al periodo 1853-1880, quedarán como un relevamiento inicial y fundamental para conocer las ideas sociales en la Argentina. No vemos siempre una clara congruencia entre lo que se afirma de estos personajes y sus referentes del socialismo francés y no nos parece adecuada la denominación "socialismo romántico" para señalar el socialismo previo a Marx, ya que, tal como se desprende de la obra, implica subordinar el socialismo al liberalismo, que por momentos es revolucionario pero siempre antisocialista. No consideramos que el socialismo sea una doctrina pura e incontaminada, definible en cierta perfección abstracta, pero las elecciones históricas y políticas implican partir de algún límite, que quizás Horacio Tarcus lleva demasiado lejos.

\section{Referencias}

Alberini, C. (1934). La metafisica de Alberdi, en Archivos de la Univesidad de Buenos Aires, IX, junio-septiembre. Disponible en www.archivofilosoficoargentino.info.

Díaz, H. (2020). De Saint-Simon a Marx. Los origenes del socialismo en Francia. Biblos.

Echeverria, E. (1873). Dogma socialista. Carlos Casavalle.

Echeverría, E. (1981). Antología de prosa y verso. Editorial de Belgrano.

Lenin, V.I. (1946), Tres fuentes y tres partes integrantes del marxismo [1913], en V.I. Lenin, Obras escogidas. Problemas.

Tarcus, H. (2016). El socialismo romántico en el Río de la Plata (1837-1852). FCE.

Tarcus, H. (2020). Los exiliados románticos. Socialistas y masones en la formación de la Argentina moderna (1853-1880), 2 vols. FCE. 